\title{
Multi-layer Aspects of Information Manipulation in the Intercultural Area
}

\author{
Justyna Pilarska \\ Department of Historical and Pedagogical Sciences \\ University of Wroclaw \\ justine p@op.pl \\ Arkadiusz Urbanek \\ Department of Historical and Pedagogical Sciences \\ University of Wroclaw \\ urbanek.arkadiusz@vp.pl
}

DOI:10.5901/mjss.2014.v5n22p4522

\begin{abstract}
The reflections focus on various aspects of manipulation taking place in the cultural borderland between the majority and the minority. Information manipulation has been subject to exploration from two perspectives. On one hand it concerned activities of the minority trying to take advantage of the majority's lack of knowledge of the minority culture. Such situation combines lack of intercultural education with issues tackling international laws that provide protection for cultural (and religious) diversity. For this purpose, the analysis embraced results of research carried out within execution of Polish law procedures of dealing with imprisoned foreigners. In such circumstances the prison service staff are obliged to respect cultural (and religious) diversity. Nonetheless, the question to what extent they are familiar with the specificity of the foreigners' (for instance Muslim) cultures remains open. The second aspect of the analysis considered the opposite, i.e. when public authorities such as media manipulate the social majority in order to shape their opinion on diverse culture, consequently discriminating the minority. Islamophobic content promoted in public discourse often serves as tool of discriminatory practices, generating deformed image of the "other". Manipulating with islamophobia provides another perspective of this issue, hence the media content concentrated on islamophobic discourse on TV or Internet constituted the second aspect of exploration. The analysis embraced content that - relying on stereotypes and misconceptions - builds up distorted image of a cultural difference exemplified by Muslims.
\end{abstract}

Key words: interculturalism, intercultural education, manipulation, islamophobia, media, the prison system, prison

\section{Introduction}

The quality of social relations at the meeting point of different cultures remains a challenge for research in various fields of science. Moreover, it constitutes an essential area of generating new knowledge and experiences of the citizens of Eastern Europe, where migration processes are dynamising integration, legal and educational policies. USA or the countries of Western Europe display greater experience in establishing areas for diverse cultures, as a result of longer tradition of multicultural societies, to recall consideration for the integration efforts undertaken in France as early as in the 1930s (The League of Nations considered French policy as a modern role model at that time). Yet, despite number of such positive experiences, discrimination against various representatives of diverse cultures is palpable, although the conflict does not result from different approach to activation models but concerns integration policy (Kymlicka, 1995). For instance, British scholars emphasize the significance of this problem, hence according to A. Bloch assimilation of immigrants (including Muslims) by the British society in the 1970s backfired, as the culturally diverse not only opposed this process, but became subject to volunteer marginalization. Thus, in order to protect own diversity they failed to follow administrative efforts of assimilation, generating the source of racism symptoms as a result (Bloch, 2002).

Mutli-aspectuality of intercultural education in this regard is reflected in various scientific publications as well as quantitative and qualitative research projects. Therefore, economy, for instance, focuses on the issues of understanding 
American, European or Arabic world of business with paramount importance drawn to cultural factors, rather than accessibility of communication channels. It stems from the idea that synergy and understanding predominantly contribute to business efficiency and stability (Kung, 1997). Correspondingly, ethics of intercultural business and administration does not result from the quality of applied language, but from its culturally determined specificity and functions, particularly if such diverse cultures as the European and Muslim are taken into account (Caputo \& Heather \& Crandall, 2012; Rubin 2011). Likewise, searching for intercultural synergy intersperses the world of global fashion, indicating changes in traditional Muslim clothing, as reflected in the fashion magazines such as „ELLE” or „Arabian Woman”, mirroring the tendency of a specific evolution in fashion industry following interpenetration of Muslim and European traditions (Kilicbay \& Binark, 2002).

Yet, European educational area seems to provide potentially conflict-generating discourse in terms of schooling, symbolism (such as the issue of religious symbols in Europe) and social power, to recall the case of banning hijab in France, Islamic education in Western Europe, or etc. (Shadid \& Van Koningsveld, 2008).

The issues of intercultural relations are also reflected in the area of law and system of justice, which remains particularly precarious and conflicting as it entails the clash between trends of repressive versus educational policy towards prisoners (Werner, 2007; Pratt \& Brown \& Brown \& Hallsworth \& Morrison, 2005). It is even further challenging as far as culturally diverse foreigners breaching law are concerned. It is therefore worth to analyze the situation in cultural borderlands (intercultural areas) in the context of total institutions, as it then concerns not only formal or legal issues, but the procedures of dealing with foreigners subject to international and domestic legal regulations. This, however, does not imply that the practices and interpersonal relations (particularly in total institutions) follow these directives, involving not legal, but social problems. Legal guarantees for the protection of cultural identity, religious freedoms and customs can therefore bring about a dangerous area of manipulation. The minority, utilizing such guarantees, can take advantage of own cultural diversity to establish a privileged stand towards the majority. Such threat is particularly challenging within system of justice as it consequently rouses opposition towards the privileged position of the perpetrator, if such person demands own protection.

The problem of synergy between the minority and the majority is essential for the social and cultural discourse, although the review of international literature proves the issue of intercultural relations in prisons is rather underappreciated. In most of the international publications the focus of attention is on rehabilitation schemes and widely-perceived education of the prisoners, including juvenile delinquents and women (Baldi, 2009), with lifelong learning in prisons becoming a premise of protection against recidivism (Warner, 2007; Rose, 2004). Nonetheless, little attention is paid to the education integrating culturally diverse prisoners, as there are no publications highlighting the process of establishing an area of understanding between the sentenced and the prison staff. If issues of integration are taken scientifically into account, it is rather in the context of barriers of social assimilation occurring upon the process of readaptation of former prisoners (Warner, 2002). The review of Polish literature on the subject does not provide with such findings either, scarcely admitting that legal procedures are insufficient in this regard. Hence, it is worth to tackle the issue of the image of personal relations of prison staff with the sentenced foreigners. Such perspective shifts the significance from formal and legal aspects to personal experiences and views. Ergo, these factors generate area of synergy versus discrimination, in other words understanding versus mutual distrust. The answer to such question requires launching an in-depth qualitative research, not focused on seeking correlation between objective variables, but analyzing personal experiences and judgments.

\section{Method}

\section{Researched Group}

The field research has been carried out in two, complimentary panels. Such sequence of research refers to the two-stage process of gathering source data upon qualitative research, as established by J.W. Creswell (2003). The procedure of sequential research is applied when answers to research questions require concurrent general and precise procedures, taking into consideration not only the time of generating data but also the research weighting. The objective of the latter was to reveal the areas of manipulation risk from the cultural minority. However, adopting wider perspective of perceiving the problem the research project, divided in two panels, was subject to Sequential Transformative Strategy (Tashakkori \& Teddlie, 2003). Consequently, problem areas were generated out of general data (collected within the country) in order to conduct precise, individual interviews. Thereupon, two types of source material were established. The first panel concerned analysis of source, i.e. official documentation gathered in the years 1992-2012. In that period over 190 complaints had been submitted, out of which the exploration embraced 125 complete documentation addressed to 
Helsinki Foundation for Human Rights in Warsaw, concerning applications sent by those in remand centres or prisons in Poland.

The second panel embraced direct interviews with prison staff officers that work as prison tutors (14 persons). Such selection of the respondent group corresponded to the procedure of qualitative research (the criterion of having experience working with foreigners was predominant).

\section{Source material}

In the first panel of triangular research the source material referred to complaints submitted by remanded or/and sentenced foreigners in the territory of Poland. The material consisted of unstructured documentation, i.e. such that had not been generated, but found by the researcher. The complainants were representatives of diverse cultures and nationalities, from 17 countries altogether. Documents were written in Polish, Russian, English, and German. Three of them were excluded from the analysis due to their illegibility and lack of researcher's competence to analyze such text, as it had been, for instance, addressed by an Iranian citizen, whereas documents were prepared in Arabic. The gathered material was collected upon preliminary survey of the archive holdings at Helsinki Foundation for Human Rights in Warsaw, which is an international institution of apolitical character that provides legal assistance in all the cases when the risk of infringing rights of individuals occur.

As far as the second panel is concerned, the material comprised of interviews with prison tutors working with sentenced foreigners, particularly Muslims. The interview discourse was translated into the pattern of mental maps in line with the principles of the research procedures. The map reflected both the opinions on the quality of intercultural relations as well as depicted "negotiating" personal approach towards those culturally diverse.

\section{Procedure}

The first research panel provided general information i.e. at national level. Due to the formula of source documents the analysis procedure embraced two levels of personalization of the material in accordance with the strategy of qualitative research. The first stage included working out a set of problem matrix in a table with data collection. The structured matrix provided key tool of selection for the source material, as according to $\mathrm{H}$. Wolcott such proceedings constitute a priority of professional qualitative research (Silverman, 2007). Upon second stage of analysis decoded source material was subject to selection, scaling down the cases to representatives of Muslim culture only. After the second phase 8 pieces remained out of 125 documents.

The second panel constituted an essential part of the research and embraced direct interviews carried out in 5 penal institutions in the eastern part of Poland. In terms of theory while seeking common area of beliefs and convictions the research procedure relied on the assumptions of theory of social constructionism by Kenneth George (2009). Direct strategy of gathering data was subject to the interviews technique of RepGrid, rooted in theoretical foundations of personal construct psychology by George Kelly (1955), whose key theoretical assumption highlights the thesis that people maintain their own interpretation of social occurrences, whereas its quality depends on the gathered life experiences. Moreover, according to Kelly, scientific research shall aim to reveal internal representation of the external world, referred to as a personal construct. Consequently, the standard RepGrid interviews included three following procedures.

The first objective was to depict the situation of Muslim prisoners in Polish penal institutions. It was recalled by the respondents and encoded in a list of adjectives, reflecting their situation in a prison as a total institution. At this level, the respondents were selecting such notions from the list that were in their opinion contradictory or provided polar opposites, subsequently becoming a point of departure for a consecutive interview.

The second procedural element concerned the process of exploring the contents of personal constructs, i.e. information on perceiving mutual, intercultural relations. This stage revealed two additional aspects, as on one hand it embraced formal issues, i.e. interpretation of the quality of intercultural relations with Muslim prisoners according to the official policy, and on the other - facilitated the search for personal perspectives and descriptions of these relations. The qualitative research did not concern the measure of knowledge and professionalism of the state officials, but rather their recognition of own points of view. In this regard the procedure of research corresponding to the RepGrid technique proved to be most effective, as it referred to the assumption that interviews should be conducted not within framework of additional but confronting questions, searching for arguments contradictory to the claimed theses. Thus, the role of the researcher was to explore the respondents' opinions opposite to the one they expressed. 
The third element of the procedure relied on the analysis of the mental maps, i.e. the image of the interviews account, depicting contradictory arguments. This level generated personal views and judgments concerning intercultural relations of the prison staff and foreign prisoners. Therefore, it was crucial at this stage to explore the constructs, i.e. to search for the content not directly nor immediately indicated by the respondents (Neimeyer \& Anderson \& Stockton, 2001).

\section{Outcomes}

The outcome of the first panel of the general research embraced information on legal, organizational and social problems occurring within the area of Polish system of justice while dealing with forefingers. The direct result of the documents analysis was structured in matrix depicting the sequence of occurring problems. The results of the second stage of research referred to the practical problems that can bring about the risk of manipulation at the meeting points of cultural diversity. As a result of direct research mental maps for each respondent were generated. Within conclusions it was crucial to set up the image of two strategies of prison tutors' approach towards Muslim prisoners. Such strategies by far result from personal experiences and perspectives, concurrently revealing an interesting perspective between the official legal discourse and personal beliefs. Deliberate selection of respondents was of key importance for the research procedures, as it embraced those individuals who have had few years of experience in working as a prison tutor and have been in direct relations with the sentenced foreigners.

\section{Categories of problems emerging within foreigners' complaints concerning Polish system of justice}

It is worth to stress the significant disproportion between the number of complaints concerning the system of justice in case of remanding and sentencing. According to Polish Penal code, foreigners (similarly as Polish citizens) suspected of having committed a crime are subject to remand as a way of temporary isolation determined by the court. In the meantime procedures of gathering evidence are launched so consequently such person can be whether released from remand or sentenced by a lawful verdict. In the latter case, on the basis of final and binding court decision, such suspect is deprived of own liberty, i.e. is subject to regulations concerning sentenced, not temporarily arrested. Disproportion of complaints accusing institutions of the system of justice of breaching human rights was overwhelming within the reported cases of remand. Complaints submitted to Helsinki Foundation for Human Rights from those sentenced and deprived of liberty were scarce (with the proportion 9:1).

The range of accusations embraced generally suspicion of violating human rights, with particular emphasis on the three following aspects:

a) Violation of the right to cultural diversity accusing system of justice officials to hinder or prevent the prisoners from manifesting behaviours adequate to maintenance of cultural identity or own individuality. Within this range accounts made by Muslims occurred crucial due to significant discrepancies between local, European culture and the Muslim customs. On the other hand, the matter-of-factness of these complaints occurred pivotal, as the conflict referred to the lack of understanding of different course and objectives of socialisation and customs. Hence, the accusations that forcing someone to clean own prison cell provides the apparent evidence of violating cultural diversity. This aspect of everyday life reality in prison was most frequently addressed in the complaints by the Muslims, who stressed that socialisation of men in their cultures prepares to completely different social roles than cleaning, what is apparently an attribute of women and found offensive as activity for men. Similar aspect was tackled within complaints about the lack of possibility to arrange own formal issues with men, as women prison staff are perceived as unequal partners in conversations. Justification of this fact also concerned cultural diversity and the fact that Muslim tradition does not grant equal rights to men and women. According to the Muslim prisoners forcing them to clean their cells and unwillingness of prison staff to isolate women from dealing with Muslim prisoners provided key manifestations of lack of respect for the Muslim culture. In this regard Polish prison staff were sued on the ground of violating the law protecting cultural diversity of the sentenced.

b) Violating the right to be treated equally regardless of the origin and race was tackled with regards to the court and prosecutors, accusing these institutions of discriminatory sanctions of remand towards the forefingers. Muslim complainants perceived remand as a result of excessive lack of trust towards them, assuming that in similar cases Polish citizens would be treated with less rigidity. In their opinion foreigners, as "the others", are suspected of wanting to hide out from the police or escape. Similar complaints concerned unjust and excessively procrastinated period of remand, due to apparent tardiness of the organs of state. Indeed, it must be highlighted that as far as foreigners are 
concerned, significant role is played by procedural aspects of the investigation, particularly within translation of court papers, appointing witnesses, translators or interpreters. Such obligations, resulting from international and domestic law, can procrastinate the proceeding period at persecutor's office. It arises a lot of controversies in Poland, especially in the context of protection of foreigners against unjust treatment by the organs of state. The directives for (not only Polish) courts are vital in this regard, as regulations within anti-discriminatory procedures origin from the indispensible human rights discourse. On the basis of actual verdicts of the Court of Human Rights there are crucial premises of cautiousness regarding foreigners while approaching the occurrences of remanding, apprehending or procrastinating these procedures.

c) It is worth to highlight insignificant number of complaints (5) tackling direct violation of the right to freedom of thought, conscience and religion or belief. The complaining Muslims claimed that upon their remand they had been deprived of their right to contact Muslim clergy, additionally stressing lack of prison staff activity in alleviating conflicts between the sentenced Poles and Muslims. In these cases no evidence was found to confirm such occurrences, as in the first case no such event had been reported, and as for the latter situation it was not grounded in mutual disinclination towards cultural diversity, but had to do with personal features of the characters of the sentenced men.

\section{Perception of intercultural relations by prison tutors}

The above-recalled analysis of the general problems in the intercultural area is reflected in field research, accomplished within the second panel. The same problems reported after analysis of complaints were addressed by the researched prison officers. Conclusions from the research highlight, however, more important issue, namely the strategies adopted by prison tutors in relations with Muslims and foreigners on the whole.

Table 1 depicts the strategy of understandings of difficult situation of the sentenced foreigners. Such approach corresponds to the stands of international law within European community, such as Recommendation $\mathrm{nr} R(84) 12$, adopted by the Committee of Ministers to member states on the European prison rules concerning foreign prisoners, indicating that the organs of the system of justice are obliged to search for organizational and legal solutions aiming to alleviate objectively more difficult situation of culturally diverse prisoners. Tendency of understanding and support emerged within interviews with younger and less experienced prison staff, aged 25 to 30 , with 2 to 5 years of working experience. The procedure of the interviews embraced recognition of the situation of culturally diverse prisoners within a list of adjectives. Nonetheless, personal opinion on the quality of mutual relations came across as of paramount importance, with emphasis on the expectations of the foreigners towards the prison staff, mirroring the area of personal efforts, i.e. on the basis of own interpretations the respondents tried to adapt such a solution that would favor support and assistance. It is worth to mention that as far as Muslims are concerned no information on manipulation from their side was reported. Moreover, within such intercultural relations no situation where it could potentially emerge was reported either. The clue of the discussed dilemma (Table 1 ) concerned the conviction that respondents should search for such solutions to meet Muslim's expectations within legal regulations and own activity. Such approach explains why prison tutors themselves tried to seek knowledge on the specificity of Muslim culture, particularly tackling their religious rites and customs. The prison staff's personal intercultural education turned out indispensible in provision of conflict-free presence in the prison, protecting from breaching the right to respect religious and cultural diversity.

Yet, another strategy was displayed by tutors with greater experience in dealing with sentenced foreigners, embracing those aged 35 to 45 and with more than 10 years of working experience. The range of qualitative research did not undertake the issue of correlation between working experience and manifested opinions, but it is worth to stress the context that provides justification for different points of view. Namely, in the 1990s there was a massive wave of income of foreign prisoners in Polish penal institutions, thus in the years 1995-2002 their number rose from 1496 (in 1995) to 1550 foreigners (in 2001). Nowadays, the number reached 564 in the year 2012 and 549 in 2013 respectively. Moreover, it needs to be taken into consideration that greater number of foreigners undeniably generated greater area of conflicts involving prison staff. It is possible that such experiences of those with longer working experience created strategies of cautiousness in intercultural relations, what confirms the analyzed personal constructs revealed within the RepGrid interview technique.

Cautiousness tackled the lack of trust and conviction that the sentenced act instrumentally, trying to engage the staff in their manipulating "game", which aim is to gain maximal personal benefits, by taking advantage of own cultural diversity. Table 1 depicts the same issue in relation to Muslims in the first panel of research, including unwillingness to perform daily duties. According to the respondents such game is indeed intricate and risky for the system of Polish penal institutions as intercultural relations can generate dangerous precedence tackling confrontation of formal procedures (such 
as searching suspects' belongings or a body search, protection of sacred objects, or protection against nudity). Moreover, in their opinion it is truly challenging to make decision in this regard, recognizing which of the Muslim claims are legitimate, and which are a manifestation of manipulation.

The above reflections lead to two key conclusions. On one hand there is a personal conviction that the sentenced want to manipulate the prison staff unwilling to cooperate, what in turn involves staff cautiousness in making decisions concerning foreigners. On the other hand, prison staff seem underprepared for such situations, as they learn about the specificity of Muslim customs and traditions on their own, or simply approach them with mistrust. It therefore highlights the fact that intercultural areas can provide favorable circumstances for manipulation, if no sufficient intercultural education is applied. Otherwise, the minority can take advantage of the majority's unawareness of cultural differences, opening up the area of information manipulation.

\section{Manipulation in the media}

There is also another side of this complex phenomenon, namely information manipulation displayed by the media (representing the majority), distorting the image of the Muslim minority in multicultural (or intercultural) environment in Western Europe. Radio, television, film, and other products of the media culture provide materials out of which individuals shape their point of view on the aspects of life unfamiliar on a daily basis, for example the cultural specificity (customs, patterns of behaviour, set of values, religious rites etc) of the Muslim minority. Thus, the media forge the notion of what is culturally "own", "strange" and "the other", followed by the sense of religion, ethnicity and nationality structuring the social world on the ground of "us" contrasting "them". Consequently, they shape the view of the world of the society members and their hierarchy of values, providing "the symbols, myths, and resources through which we constitute a common culture and through the appropriation of which we insert ourselves into this culture" (Kellner, 1995). Therefore, as the recipients and creators of culture, members of the society are immersed in the media realm and it is essential to learn ways to interpret, understand and - most of all - critically analyze meanings such channels convey. Hence, the media content should not be simply uncritically acknowledged. Otherwise, obeying rules recognized by the majority would entail presenting viewpoints solely in line with the mainstream, favouring the majority discourse and simultaneously marginalizing cultural difference and its representatives.

Nowadays, where the role of the media is fundamental not only in reflecting, but also generating the reality around, the image of the latter can be manipulated to misrepresent not only actual facts but also members of the minority culture. Thus, the representation of Islam and Muslims in the European media are often referred to as the "alien other". Such, as matter of fact, misrepresentation boils down to a contemporary notion tackling racism, i.e. Islamphobia, that stems from cultural representations of the recalled "other" originating from Muslim culture. Although attempts to define Islamophobia have not been entirely successful and no single definition is officially acknowledged, it can be recognized that "Islamophobia groups together all kinds of different forms of discourse, speech and acts, by suggesting that they all emanate from an identical ideological core, which is an 'irrational fear' (a phobia) of Islam" (Cesari, 2008).

For this purpose and in order to convince the culturally insensitive and/or unaware majority the treatment of Islam representatives in the media frequently involves such themes as "threat", "extremist", "fundamentalist", "fanatic" or "terrorism". Of course the approach to Islam varies from one country to another, as much as the extent to which Islamophobia exists. Still, it can be argued that the media in most of the European countries present a somewhat biased view of Muslims and Islam, although differences may lie in various level of acceptance of multiculturalism, manifested in mutliaspectual social discourse or degree of implementing paradigms of intercultural education.

There is palpable reinforcement of the idea that cultural norms are constituted by the majority, thus, consequently, "others" exist on the peripheries of the society's attention. Otherwise, if at the forefront and in the focus of attention, it often takes place in some negative, usually "terrorist-related" context. As a result, such approach reinforces the minority members as "others", thus the majority (the media) hold the assumption that culturally diverse minority members think and act in unified (universal) stereotypical ways. The report on Muslim issues commissioned by Channel 4 Dispatches and carried out by the Cardiff School of Journalism, Media and Cultural Studies provided interesting data in this regard. In their Report "Images of Islam in the UK. The Representation of British Muslims in the National Print News Media 2000-2008" (Moore \& Mason \& Lewis, 2008) the research team examined 974 stories, revealing that about two-thirds of all "news hooks" for stories about Muslims involved: terrorism (36\% of the stories), religious issues such as Sharia law highlighting cultural differences between British Muslims and others (22\%) and Muslim extremism (referring to figures such as Abu Hamsa). By contrast, only 5 per cent of stories were based on problems facing British Muslims. This biased approach can serve as an 
example of how the media shape the image of Muslims by regular and systematic infiltration into regular society, leading to legitimization of the phenomenon of Islamophobia.

Repercussions of such phenomenon are far-reaching. According to the Gallup institute and its report "Islamophobia: Understanding Anti-Muslim Sentiment in the West (Gallup Poll, 2008), Muslims at large do not feel respected by the members of Western societies. Respectively, significant percentages of several Western countries share this stand, claiming the West does not respect Muslim societies. To recall some statistics, $52 \%$ of Americans and $48 \%$ of Canadians say the West does not respect Muslim societies, with only smaller percentages of Italian, French, German, and British respondents agreeing. Applying various research tools and global polling efforts Gallup has collected a wealth of data detailing public opinion about various aspects of respect, treatment, and tolerance related to Muslims worldwide. The survey provided data on perception of Muslims as intolerant of other religions, regardless of the fact whether respondents personally knew any Muslims or have had contact with their community members on a daily basis. Such results can, unfortunately, find justification in many aspects of social, cultural and political discourse, including the media. It is therefore explicit that majority of respondents with regard to attitudes towards Muslims (and prejudices within) manifest significantly negative approach, as - for instance - $73 \%$ of the researched claim that most Muslims around the world are not accepting people of races other than their own, with similarly high result (63\%) in case of the opinion that apparently most Muslims around the world do not want peace (sic!).

Another alarming conclusion can be withdrawn from Gallup data collected in 2008 from representative samples in Germany, France, and the U.K., considering issues tackling social and cultural integration of Muslim communities in these three countries. Paradoxically, despite the fact that majority of adult population in these countries admit that people from minority groups enrich the cultural life of their nations, sizable minorities of these respondents express fear about certain aspects of Muslim culture, including $28 \%$ of respondents from the U.K. claiming people with different religious parties threaten their way of life.

The question whether such attitude is a consequence of the negative images of Muslims reproduced by the media remains open and worthy of researching attention. Nonetheless, it must be emphasized that such one-dimensional and monolithic view of Islam does not take into consideration any internal differentiation within Muslim culture and community.

Interestingly, as early as in 1997, The Runnymede Trust report into Islamophobia in Great Britain stated that Islam was inherently seen as being the 'other' to the West, hence reinforcing the 'them' versus 'us' dualism, (Runnymede Trust, 1997). In 2004, after 9/11 and the initial years of the Afghanistan and Iraq wars, The Runnymede Trust produced a followup report in 2004, founding that the aftermath of the terrorist attacks had deteriorated the quality of British Muslims' life due to reinforced prejudices and stereotypes of Muslims functioning in the media (Runnymede Trust, 2004).

By consuming the media content society members identify and associate themselves with basic approach towards culturally different individuals. Consequently, individuals justify their actions, beliefs, values and perception of the world with reference to the constructions presented by various mass media forms. Unfortunately, such "methodology" may be deceiving as it often makes inequalities such as discrimination of Muslims an inherent part of the cultural and social discourse. To justify such critical approach it is suffice to recall some of the examples of media literally bombarding recipients of the news (often taken out of context) accompanied by images of Muslims burning American flags in rage, women covered from head to toe expressing their anger at military actions in the Middle East in front of US or other western embassies, or Muslim children holding placards bearing the face of alleged terrorists related to al Qaeda in Afghanistan or Pakistan. Such visions are often followed by despicable and sensationalist headlines proclaiming that "This fanaticism that we in the West can never understand", "experts" claiming that "Islam taking over, Europe soon to be unrecognizable", or Tony Blair warning of "Growing Radical Islam Threat".

Although the role of the media is undoubtedly difficult to categorize and the media cannot be literally and solely blamed for Islamophobia, particularly as far as the translation of attitudes and ideas into incidents and actions are concerned, its role cannot be entirely dismissed either. None of the recalled reports suggested that the media directly caused or, indeed, were responsible for any reported or identified act of aggression or significant change in attitude, nonetheless they play a major role in the formulation and establishment of popular perceptions in the public sphere, also concerning Muslims, hence their role cannot be underestimated in this regard. Moreover, even if some media sectors seek to remain balanced and objective, many are still unlikely to contribute to informed discussion and debate amongst, and about, Muslims (An academic report commissioned by the Mayor of London on behalf of the Greater London Authority, 2007).

On the basis of semiotic analysis of the media content regarding Islam within Western European framework ranging from quantitative content analysis to qualitative study (e-versions of the major newspapers such as the Daily Telegraph, Washington Post, or large 
international cable and satellite television channels such as BBC, CNN and other news corporations), it was possible to reveal some overall assumptions generated by the media contents. It led to the conclusions that most Western media:

utilize the 9/11 attack to forge homogenous image of Muslims linked to negative terms like "terrorist", correspondingly depicting Islam as equal to "fundamentalism", "extremism" and "radicalism"; (according to Gallup research significant proportions associate Muslims with terror as $23 \%$ of Germans, $25 \%$ of the French, and $34 \%$ of the British say that Muslims are sympathetic to al Qaeda); respectively reproducing negative and unwarranted portrayals of Islam and Muslims as terrorists, terrorist sympathizers and subversives;

[ do not mention or do not give a fair hearing to alternative views, understandings and opinions concerning Muslims;

[. seem unlikely to contribute to the process of diminishing levels of acts of unlawful discrimination by non-Muslims against Muslims;

[ apply frequently emotive, immoderate, alarmist or abusive tone of language in the context of Muslim/lslamic discourse;

[ frequently distort, exaggerate or oversimplify facts while reporting;

[ perceive Islam as incompatible with democracy, hence the assumption that there is no common axiological ground for the world of Islam and the West duly imposing the view that there is little if no chance whatsoever to empower pluralism within multicultural societies with Muslim minority;

[. find accepting Islamic minority in the societies (regardless of complex social implications) entails apparent loss of the "indigenous" unique identities;

1. project the image of Muslims as not loyal to their new homelands, what may be linked to the fact that many Western European citizens tend to avoid having Muslims as neighbours (according to Gallup research between $16 \%$ and $21 \%$ of people in France, Germany, and the U.K. would not like Muslims as their neighbours);

0 consider different Muslim practices and relationships threatening since $16 \%$ of Germans, $30 \%$ of British, and $39 \%$ of French said in the Gallup survey that wearing hijab is a threat to European culture;

[ are likely to provoke and increase feelings of insecurity, suspicion and anxiety amongst non-Muslims;

0. perceive Muslims differently (unfavorably) from members of Western societies in their level of integration and openness to people of other faith;

[ do little to reduce the recurrence of misrepresentations and stereotypes concerning Muslims.

Taking it into account, it can be assumed that the mass media are powerful in shaping, influencing and entailing stereotypes, prejudices and attitudes to "others" by manipulating information, acknowledging the (biased) reality. They are also powerful enough to "instruct" how to perceive cultural difference, resultantly conforming to the dominant system of norms, values and practices. Thus, it is pivotal to gain critical approach to the media content in order to resist the information manipulation in intercultural areas. It is, moreover, equally crucial to analyze information within the social relations and system through which given culture is produced and consumed, bearing in mind that the media articulate dominant values and political ideologies (Kellner, 1995).

Hence, multicultural education provides key mechanisms enabling society members to read and interpret one's culture manifested through media critically, facilitating examinations and critical scrutiny without prior prejudices often conveyed via media channels, generating one-sided orientations to Islam. And although media should help to organize multicultural information and ideas, it turns out that they very often unjustifiably emphasize limited information about a minority group (Keever \& Martindale \& Weston, 1997), shaping and generating so called "pseudoenvironment", unreliably reflecting the complexity of the social and cultural reality (Boorstin, 1961).

Moreover, since contemporary societies are structured by opposing groups who manifest diverse ethical, axiological and even political ideologies it is important to realize how media culture reproduces certain forms of discrimination against members of cultural minorities. Generated negative perceptions, prejudices and discriminations targeted against Muslims provide the example how lack of essential intercultural skills and knowledge can enable manipulation of information in the media. Therefore, the existence of Islamophobia is something to be addressed, regardless of the degree to which individuals expressing this phenomenon have particular views of Muslims in their communities. It seems that the major challenge today involves getting accurate and verified information, hence it is worth to pose a question how to counteract such unjust vision of the cultural minority that constitutes part of the multicultural area. It is undoubtedly challenging to contradict such power as the mass media, but as far as multiculturalism is concerned, education can provide effective tools of equipping 
members of culturally diverse societies with skills and abilities to basically "think out of the media box". Therefore, the representation of Muslims in the Western media needs to undergo a significant change, so that Islamophobia could be replaced by the paradigm of interculturalism.

\section{Intercultural education versus information manipulation}

Intercultural education displays a real potential of fighting against dominant encoded meanings, producing own critical and alternative readings, contrary to information manipulation generated by the minority or/and the majority, utilizing multiplicity of perspectives and critical methods. Ergo, such education requires a multicultural approach that sees the importance of analyzing the dimensions of cultural diversity, including approach to Islam, consequently entailing critical media pedagogy that enables individuals to resist the media manipulation and to increase the sense of autonomy of all members of the intercultural area.

Intercultural education can empower individuals in resisting the dominant meanings within the media cultural products, or state policies concerning law, consequently producing own meanings. It can help promote development of more critical consciousness regarding Islamic culture, providing a broad, comprehensive framework to undertake multicultural dialogue, free from prejudice and misconception. Moreover, it acknowledges that all the society members, including Muslims, have the right, ability and even the obligation to participate fully in shaping its cultural and public discourse. It might be carried out by providing with certain perspectives of some social aspects such as cultural diversity, enabling critical analysis and interpretation. Significantly, it does not come down to - as in case of the media - imposing perspectives and understandings of the reality, but to reinforcing the relative, heterogeneous and alternative approach towards this, what is commonly accepted. Therefore, intercultural education can encourage to gain individual and non-biased view on social problems, create new ideas and relate them to own experience within intercultural area, accepting seemingly cultural controversial concepts.

To prevent Muslims from being marginalized, discriminated and excluded from social, political and civic life in Europe intercultural education is essential. Since unawareness of the cultural differences opens up the area of manipulation for those holding power (such as the media or legal authorities), it is worth to address the issue of not only intercultural education, but some crucial aspects within, namely intercultural competences. Such competences should embrace:

․ knowledge concerning cultural differences, entailing different behavioural patterns, set of values, etc;

1] cultural identity expressed as a behavioural, cognitive and emotionally constructive approach towards own culture (healthy balance between chauvinism and lack of attachment to own cultural roots);

[. Social initiative (reaching beyond own cultural circles);

[ i intercultural sensitivity expressed by active attitude towards representatives of other cultures;

[ empathy as a key feature of a member of multicultural community, manifested by understanding and reading appropriate context of the emotional and motivational areas of other people;

[ open-mindedness towards cultural complexity of the social reality around;

[] communication skills including the ability to adjust communication style to other cultures.

Appropriately, an intercultural, competent person - no matter if working in a total institution as prison or being a part of the media world - is able to see the relation between different cultures, displaying the ability of meditation, interpretation, as well as critical and analytical understanding of the personal culture and the culture of "other". Thus, intercultural members of the society do not accept the social reality passively nor take it for granted, but actively participate in the multicultural area exercising the above-recalled abilities.

In order to establish such common ground shared by all the members of intercultural area, some certain criteria should be met, including antinihilistic axiological orientation, dynamism (openness to changes), dialogue and discourse. Only such perspective enhances perception of the intercultural area as a dynamic, inspiring sphere of experiencing diversity not only in the ontological, but also moral context due to the fact that dialogue and discourse allow to broaden and widespread commonly accepted values and norms, to combine points of views and moral stands, as well as to overcome stereotypes and misconceptions. Moreover, such approach avoids the media and legislation trap of universality as only diversity can allow recognition of life orientations. In consequence, the denial of simplified tendency to universalize corresponds with the stages of intercultural learning since such approach does not negate the sheer existence of differences, does not even attempt to join them nor to reduce them to the lowest common axiological denominator, but 
allows to change the profile of a given culture towards interculturalism. It, in turn, implies the need to work out common cultural ground that would constitute a foundation for the contact in intercultural area, whether in a total institution (such a prison) or within media channels, evoking lasting understanding and permanent, ethically rooted relations that can counteract prevailing stereotypes concerning Muslims. Moreover, in the context of information manipulation, successful intercultural education could prevent from intolerance and prejudices towards Muslims. Yet, in order to implement such idea, systematic and methodical approach is indispensible.

\section{References}

Baldi, S. \& Hutner, M. \& Greenberg, E. \& lin, Y. \& Baer, J. \& Moore, E. \& Dunleavy, E. (2009). Technical Report and Data File User's Manual, U.S. Department of Education, Washington.

Bloch, A. (2002). The Migration and Settlement of Refugees in Britain, Palgrave Macmillan, New York.

Boorstin, D.J. (1961). The image of whatever happened to the American dream? Atheneum, New York.

Creswell, J. (2003). Research design: Qualitative, quantitative, and mixed methods Approaches, Sage, Thousand Oaks.

Kilicbay, B. \& Binark, M. (2002). Consumer Culture, Islam and the Politics of Lifestyle. Fashion for Veiling in Contemporary Turkey. European Journal of Communication, 17,495-511.

Kung, H. (1997). A Global Ethic in a Age of Globalization. Business Ethic Quarterly, 7, 7-32.

Gergen, K.S. (2009). Nasycone Ja. Dylematy tożsamości w życiu współczesnym, PWN, Warszawa.

Caputo, J.S. \& Crandall, H.M. (2012). The Intercultural Communication Cultural Immersion Experience Preparing Leaders for a Global Future, Symposium University of Phoenix. Journal of Leadership Studies, 6(1), 58-64.

Cesari, J. (2008). Muslims in Europe: Local and global conditions of integration in religion and democracy in Europe, Van Leer Institute, Jerusalem.

Dijk van, T.A. (2000). New(s) Racism: A Discourse Analytical Approach. In S. Cottle (Ed.), Ethnic Minorities and the Media: Changing Cultural Boundaries (pp. 27-38). Open University Press, Buckingham.

Gallup Pool. Islamophobia: Understanding Anti-Muslim Sentiment in the West. http://www.gallup.com/poll/157082/islamophobia-understanding-anti-muslim-sentiment-west.aspx

Hall S., \& Hobson, D. \& Lowe A. \& Willis P. (Ed.) Coding/decoding. In Culture, Media, and Language, (pp. 63-87). Hutchinson, London.

Keever, B.A.D. \& Martindale C. \& Weston M.A. (Ed.), (1997). US news coverage of racial minorities: A sourcebook, 19341996, Greenwood Press, Westport.

Kellner, D. (1995). Media Culture: Cultural Studies, Identity and Politics Between the Modern and the Postmodern, Routledge, London.

Kelly, G. (1955). The Psychology of Personal Constructs, Norton, New York.

Kymlicka, W. (1995). Multicultural Citizenship. A Liberal Theory of Minority Rights, Clarendon Press, Oxford.

Moore, K. \& Mason, P. \& Lewis, J. (2008). Images of Islam in the UK. The Representation of British Muslims in the National Print News Media 2000-2008, Cardiff School of Journalism, Media and Cultural Studies.

Neimeyer, R.A. \& Anderson, A. \& Stockton, L. (2001). Snakes versus Ladders. A Validation of Laddering Technique as a Measure of Hierarchical Structure. Journal of Constructivist Psychology, 14 (2), 83-103.

Pratt, J. \& Brown, D. \& Brown, M. \& Hallsworth, S. \& Morrison, W. (2005). The New Punitiveness: Trends, theories, perspectives, Willian Publishing, Cullompton.

Rose, C., (2004). Women's Participation in Prison Education: What We Know and What We Don't Know. The Journal of Correctional Education, 55(1), 78-100.

Rubin, J. (2011). Institutions, the Rise of Commerce and the Persistence of Lows; Interest Restrictions in Islam and Christianity. The Economic Journal, 121, 1310-1339. 
Runnymede Trust (1997). Islamophobia, a challenge for us all: report of the Runnymede Trust Commission on British Muslims and Islamophobia Runnymede Trust. Commission on British Muslims and Islamophobia, Runnymede Trust, London.

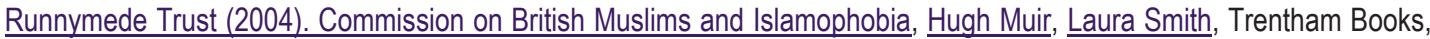
London.

Shadid, W.A. \& Van Koningsveld, P.S. (2006). Islamic Religious Education in the Netherlands. European Education, vol. 38 , no. 2 ,

Summer. $76-88$.

Silverman, D. (2007). Interpretacja badań jakościowych, PWN, Warszawa

Tashakkori, A. \& Teddlie, C. (2003). Handbook of Mixed Methods in Social \& Behavioral Research, Sage, Thousand Oaks.

The search for common ground, Muslims, non-Muslims and the UK media - an academic report commissioned by the Mayor of London, Mayor of London on behalf of the Greater London Authority, 2007.

Warner, K. (2002). Penal Policy and the Adult Education of Prisoners. In P. O'Mahony (Ed.),

Criminal Justice in Ireland (pp. 726-746). Institute of Public Administration, Dublin.

Warner, K. (2007). Against the Narrowing of Perspectives: How We See Learning, Prisons and Prisoners? The Journal of Correctional Education 58(2), 170-183.

Table 1. Analysis of the respondents' account concerning their perception of personal relations with Muslim prisoners.

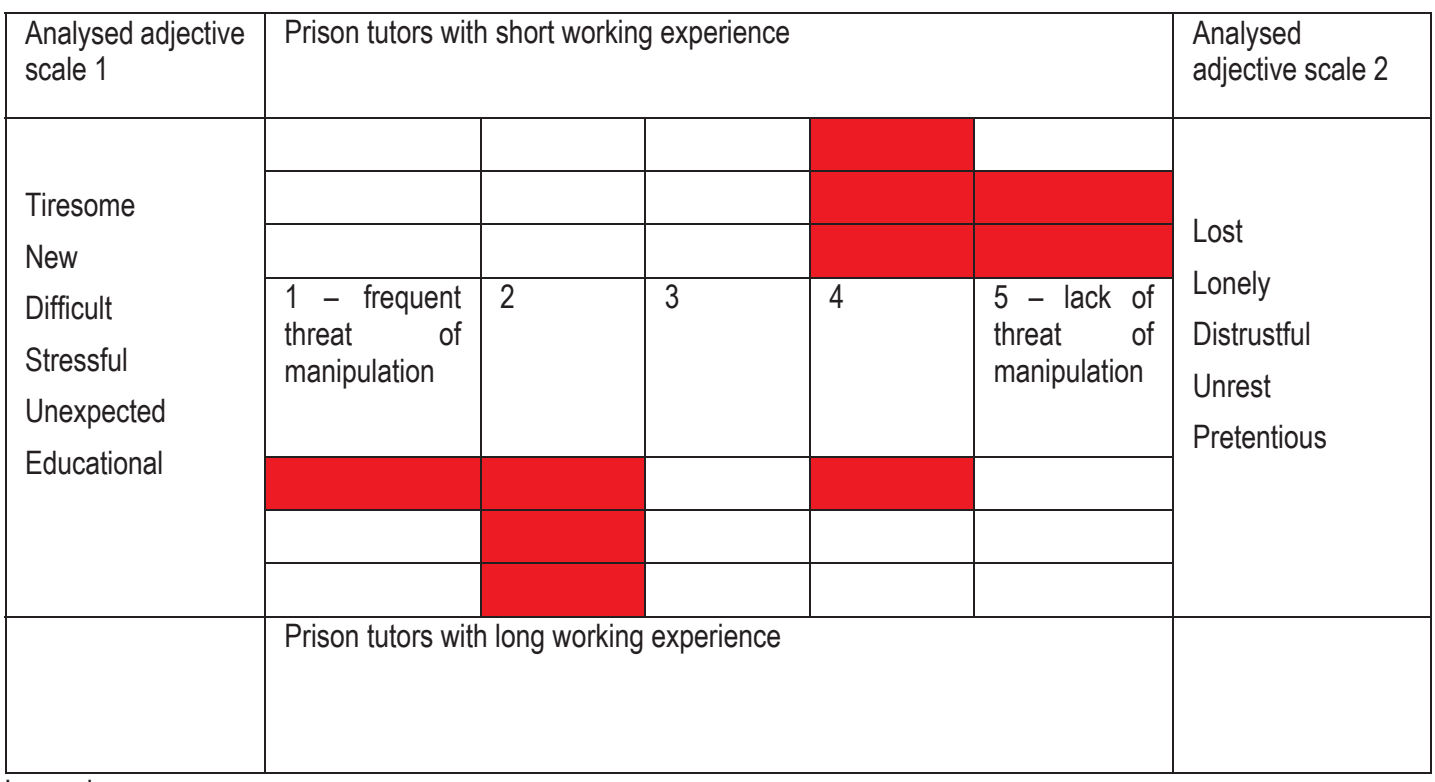

Legend:

Adjective scale - polar opposites as created by the respondents at the initial stage of the RepGrid interview with scale 1 defining adjectives chosen to depict situation in the prison, and scale 2 depicting general features of the foreign prisoner.

- intensity of the descriptions applied to depict own views on relations with a sentenced prisoner in the course of given stages of the RepGrid interview. 